\title{
Capitalism \\ and Suffering
}

\section{Abstract}

The present article is an exploration of the relationship between neoliberal capitalism and suffering in a broad sense, which includes everything from economic and physical suffering, psychic suffering in the form of anxiety, self-doubt, uncertainty and stress, to more acute suffering, such as identifiable pathologies. Its point of departure is the patho-analytic principle, that one can gain an understanding of the general psychic condition of humanity by focusing on the characteristic traits of a pathology such as, for example, obsessional neurosis, and examining the possibility that some of these characteristics are encountered in the population at large. Focusing first on evidence of severe economic suffering under the impact of what Klein calls "disaster capitalism", the argument proceeds to Parker's claim, that the typical subject under capitalism displays the character of obsessional neurosis, then to Salecl's examination of capitalism's "ideology of choice", Verhaeghe's investigation of the effects of a marketbased economy on psychic health, and Federici's claim that there are signs of increasing resistance to capitalist labour. It concludes with some prospective thoughts on Salecl's, and Hardt and Negri's diagnosis of present social conditions under capitalism.

\section{Prelude}

At the 2013 International Society for Theoretical Psychology conference in Chile there was a workshop on "The effects of the neoliberal regime on your body" in the context of the global corporatization of universities. The two women who led the workshop activities asked participants to identify their respective body-parts (for instance the head, stomach, or heart) pathologically affected by things like

\section{Bert Olivier}

Department of Philosophy, University of the Free State, Bloemfontein

OlivierG1@ufs.ac.za

\section{Keywords:}

anxiety, capitalism, choice, market, neoliberalism, resistance, stress, suffering 
work-related stress, and to present themselves in conversation with other participants as that organ or limb. They skilfully steered the group in the direction of an increasing awareness of the ever-intensifying colonization of the body by capitalist imperatives that are incrementally restructuring intellectual work at universities. I was astonished to learn how much of individuals' personal "organ-pathology" (irritable bowel, anxiety attacks, or heart palpitations) can be regarded as registering the stress imposed on one by an excessive lecturing load (the organization has to maximize profit by maintaining a lean lecturing faculty complement), with its concomitant hectic grading schedule, coupled with the ever-intensifying pressure to "publish or perish", lest you be found wanting in the scales monitoring and governing research activities at universities. This pathologization is further exacerbated by a research and teaching regime which rewards publishing in scientific journals (and adhering to compatible didactic models) which reinforce and promote the neoliberal status quo, and penalizes those, whose work appears in diverse "alternative" journals explicitly or implicitly challenging the conventional research and teaching paradigm. In sum: not even the field of intellectual work at universities is exempt from the suffering that accompanies living in a capitalist society.

"Rethinking how capital and the state have striven to transform our bodies into labor-power also serves to measure the crisis that the capitalist work-discipline is experiencing at present and to read, behind the social and individual pathologies, the resistances, the refusals, the search for new anthropological paradigms, something to which a reconstructed psychology cannot be indifferent, if it wishes to break with its history of complicity and collaboration with Power." (Silvia Federici, 2013)

"Disobedience is the true foundation of liberty. The obedient must be slaves." (Henry David Thoreau, 1847)

\section{Introduction}

It may seem counter-intuitive to associate capitalism with suffering, considering the virtually complete triumph of this economic system worldwide. Didn't Francis Fukuyama (1992) write in triumphalist mode about the "end of history" when the Soviet Union collapsed, proclaiming the marriage between liberal democracy and capitalism to be the telos which all states had been moving towards all the time? Isn't capitalism about enjoyment of commodities, ostentatious consumption, celebrity life and wealth accumulation as Žižek (1995) implies where he writes about the ironic displacement of the superego's injunction from prohibition of enjoyment to the exhortation to do just that, namely, to "Enjoy yourself!" And what is there about this that could be connected with "suffering"? One could elaborate, as Hardt and Negri do in Multitude (2005) and Declaration (2012), on the suffering that intolerable debt levels impose on people generally, and particularly on nations of the developing world (which go hand in hand 
with material suffering), but the suffering that concerns me here is chiefly of a psychic kind, as inscribed on the body. Such suffering mostly manifests itself as widespread insecurity, anxiety, stress and depression, but light may be cast on it by the characteristic attributes of a pathology (which it sometimes becomes), as I shall argue below.

\section{Suffering under "disaster capitalism"}

Before turning to this, however, a brief indication of the undeniable causal relationship between the current form of capitalism, namely global free-market (or neoliberal) capitalism, and human suffering worldwide is necessary, lest the implicit claim to this effect, contained in the title of this article, be rejected without further ado. For evidence of this I turn to that indefatigable investigative reporter, fervently hated by capitalists, Canadian Naomi Klein. In The shock doctrine: The rise of disaster capitalism (2007), Klein exposes the latest incarnation of the capitalist juggernaut as driven by the ideological imperative, to privatise every aspect of an economy (local or national) when and while communities or nations are in a state of disoriented shock in the wake of a collective natural or political trauma. Such collective traumas, followed by relentless privatisation, scrutinised by her include the effect of Hurricane Katrina on the inhabitants of New Orleans in 2005, that of the devastating tsunami along the coast of Sri Lanka in 2004, the effects of the American invasion of Iraq (of 2003) on the local population, and the economic consequences of the transition to democracy in South Africa in 1994. In the wake of all these historical events the signs of human suffering have been clearly apparent - in the aftermath of Katrina, the well-functioning public school system in New Orleans was rapidly replaced by a private, for-profit charter school system, where many older, experienced teachers lost their jobs and young teachers were employed at relatively low salaries and without the benefits that teachers enjoyed in the public school system. On the coast of Sri Lanka, where the tsunami destroyed the villages of the local fishing communities, the land was sold by the government to private development companies that built resorts for the rich in their place, with concomitant deprivation of the fishing communities of their source of survival. In Iraq American companies made a financial killing in the wake of the military invasion, while the local people suffered economically and politically. And in South Africa, where the population won a democracy at the negotiation table, they lost in economic terms because of conditions imposed on them by international financial institutions, with far-reaching negative economic consequences for poor people.

Klein (2007) elaborates on all of these examples of the cynical economic exploitation of opportunities created by natural catastrophes and political upheavals by so-called "disaster capitalism", with deleterious economic and personal consequences for the communities concerned. While these consequences undoubtedly include personal and collective hardship such as loss of employment and livelihood, I would like to 
focus briefly on the phenomenon of suicide, which is arguably a symptom of extreme, unbearable suffering. It is well known that the Great Depression of 1929 witnessed many suicides on the part of people who presumably could not perceive any hope of improvement in their economic circumstances. More recently however, suicide has again become a barometer for the psychological effects of financial and economic hardship, as Klein indicates in several instances. First there is Russia, where economic "shock therapy" (modelled on medical shock therapy, where the ground is cleared for a "new beginning") was introduced in 1992, three years after the fall of the USSR. Russia's suicide rate increased almost immediately, so that by 1994 it almost doubled from what it had been eight years before. At the same time, violent crime increased more than four times what it had been. Small wonder that Vladimir Gusev, quoted by Klein (2007: cf 238), noted in 2006 that the last fifteen years of "criminal capitalism" had decimated the Russian population by 10 percent. It was even worse in South Korea at the time of what was cynically labelled the "Asian Flu" around 1997. In 1998 the incidence of suicide increased by no less than 50 percent, with the concentration of these being among older parents who appeared to kill themselves to alleviate the economic pressure of debt on their children. Lest anyone might believe that economic disasters such as these cannot be effectively addressed, Klein provides shocking evidence that Wall Street and the IMF deliberately adopted a policy of "doing nothing" to help these countries - instead, it regarded these as opportunities for further capitalist expansion.

The reason for listing these cases of suffering under capitalist economic conditions is to drive the point home that there is a demonstrable connection between the functioning of this economic system and human hardship, contrary to what most enthusiastic supporters of it would want one to believe. It could be argued that what I have referred to above are only the most extreme instances of suffering under capitalism, and that when things are "normal", the opposite of suffering prevails, namely prosperity and happiness. In what follows, I would like to show that this is not the case.

\section{Capitalism and obsessional neurosis}

To be able to trace some kind of connection between capitalism and suffering under "normal" conditions, it is useful to turn to lan Parker, a practising Lacanian psychoanalyst, who associates suffering under capitalism with obsessional neurosis, as is evident where he writes (Parker, 2011: 42): "Those who suffer in obsessional mode under capitalism are subjects who buy into the separation of intellectual and manual labour, the separation of thinking from being, and live out the predicament of a puzzle about the nature of being as if false consciousness really did operate only at the level of the individual. Lacan argues that the question that haunts the obsessional neurotic concerns being, existence, their right to exist and whether they are alive or dead ... The 'obsessions' are repetitive ideas manifested in a series of actions from which the subject seems unable to escape.

PINS [Psychology in Society] $48 \cdot 2015 \mid 4$ 
Even though this eventually may result in suffering that is too much to bear, enough to bring someone to ask for help, it is still stubbornly tied to personal administrative strategies that contain an unbearable surplus of satisfaction - 'jouissance' is our name for this excess - within the domain of the 'pleasure principle' ..."

What Parker (2011) perceives in human behaviour under the social and economic conditions characteristic of capitalism, then, is a pattern that is reminiscent of the pathological condition known as "obsessional neurosis", recognizable in repetitive actions, excessive conscientiousness, ineradicable guilt, uncertainty, anxiety, selfreproach and doubt (see also Freud, 2011a). What is observable in a concentrated form in someone who is an obsessional neurotic, clinically speaking, returns in capitalist society as an overall pattern of behaviour, in accordance with Freud's (2011b: cf 4667-4668) remark, that individuals who suffer from some kind of pathological condition are like the "fragments" of a shattered "crystal", in whom the attributes of the whole are concentrated. Philippe Van Haute (2013) refers to this as a "patho-analytic" insight on Freud's part. By this he means an analysis and comprehension of "normal" kinds of behaviour and mental states in accordance with the characteristics of pathological conditions, where the latter are conceived of, in terms of Freud's metaphor, as "fragments" split off from the "crystal" of psychical normality. What this implies is that there is no hermetically secure distinction between so-called "normality" and pathology, as most people would like to believe - humans are all "insane"; some just more so than others). In the present context this implies that the attributes of obsessional neurosis in the clinical sense cast light on the manner in which people live in contemporary capitalist society. Renata Salecl (2010: cf 84-88) offers confirmation of this in the context of what she calls "love anxiety" in contemporary society, observing that the "protective mechanisms" typical of certain clinical conditions seem to occur "in the population at large".

Parker further reminds one that there are two sides to capitalism, both of which are inseparable from it, and connects these explicitly with the structure of obsessional neurosis, arguably in a manner which resonates with what Van Haute (2013) describes as Freud's "patho-analytic" approach. However, Parker (2011: 88) writes: "Within the very texture of capitalism as an ostensibly rational system of production and consumption and as terrain on which each individual is free to enter into different kinds of commercial and interpersonal contract with others, there are moments of unbearably excessive irrationality when relations between subjects break apart. This aspect of alienation which haunts everyday reality breaks the trust which glues market trading and the civil community together, and this alienation is 'real' as that impossible point at which the subject is torn, divided between commodity exchange and the labour process. Here the subject as such is vaunted in ideology as the psychological individual - perceiving, cognising and electing between alternative courses of action - but, in its pathological 
condition of obsessional neurosis, it is the subject as product of capitalism. Uncertainty, procrastination, powerlessness, resentment and secretive victories over a world that renders it guilty at its heart for its failure and complicity with exploitation: this is the condition of the subject which may be crystallised in a symptom taken to analysis, and then this structure of the subject can be laid bare as obsessional 'clinical structure' and the subject can speak something of the truth of the alienation that forms it."

In this excerpt Parker identifies what is most relevant for present purposes by distinguishing the two major areas where one might expect encountering signs of suffering, namely capitalist "production and consumption", neither of which is dispensable for capitalism to function successfully. Significantly, he also refers to the suffering that occurs at the interface between these two areas of economic activity (the subject "torn"), and insists that the obsessional neurotic is a "product of capitalism", alluding to some of its constitutive conditions (guilt, uncertainty, procrastination, etc.) that are reminiscent of the connections that Freud (2011) posited between obsessive and anxiety neuroses.

\section{Capitalism, anxiety and the ideology of choice}

Lest the impression be created that everyone living in capitalist society is an obsessional neurotic, clinically speaking, it is necessary to elaborate on some of the traits of social behaviour that justify the claim that this society displays a pattern which resonates with the attributes of the clinical entity, such as anxiety and uncertainty. Somewhat surprisingly, perhaps, these are encountered in precisely those areas of neoliberal society most commonly associated with the freedom of the individual, such as the liberty to choose where and how to live, what to buy and with whom one should "hook up". In her incisive book, Choice (2010), Renata Salecl probes what she calls the "tyranny of choice" in the present era. Everywhere we turn in our capitalist society, which thrives on variety, we are confronted by a bewildering array of things, items, products, services, even short-term sex partners or companions to choose from. On the one hand it is a manifestation of what one may think of as economic and social freedom, but as she shows, it comes at a price. The cost of living in these times of endless options is pervasive anxiety and depression in the face of the necessity to choose from everything that is on offer, lest one chooses "incorrectly", and has to suffer the scorn of fellow consumers, or worse, the possibility that your decision may turn out calamitously.

This situation has reached the point where one may legitimately talk about a "culture of anxiety". Salecl sums it up as follows (2010: 3): "How is it that in the developed world this increase in choice, through which we can supposedly customise our lives and make them perfect leads not to more satisfaction but rather to greater anxiety, and greater feelings of inadequacy and guilt?" Further on, she continues (2010: 8-9): "In today's 
society, which glorifies choice and the idea that choice is always in people's interests, the problem is not just the scale of choice available but the manner in which choice is represented. Life choices are described in the same terms as consumer choices: we set out to find the 'right' life as we would to find the right kind of wallpaper or hair conditioner. Today's advice culture presents the search for a spouse as not all that different from the search for a car ... The issue of choice has been a concern primarily of the middle classes in the developed world. Yet even in poor countries many have been deeply troubled by the contradictions inherent in the ideology of choice. Supposedly now free to make whatever they want out of their lives, in reality they suffer from numerous constraints ... They are encouraged to act as though they live in an ideal world and as though the choices they make are reversible, while the reality is that their economic circumstances prevent them from having much freedom of choice at all and that one wrong decision can have disastrous consequences."

Salecl (2010: 5) further makes it clear that the notion of unlimited choice is in fact a "powerful ideological tool of consumer society". She alludes to Louis Althusser's observation, that this "ideology of choice" is not something accidental, but instead something that ensures capitalism's hegemony. This is not difficult to understand. Capitalism as economic system is driven by the imperative to diversify commodities continuously to stimulate demand, and the discourse of choice that Salecl characterises so well, functions virtually imperceptibly (as ideology always does) to inculcate a collective mindset oriented according to its precepts. At the same time, the more pervasive this culture of choice gets - supposedly aimed at providing all the ingredients for optimal individual fulfilment - the more it becomes a psychological burden, and the source of uncertainty and anxiety. This explains why one of its consequences has been the emergence of "advice culture" predicated on relieving individuals from the onerous task of choosing for themselves. It is a matter of passing the buck, except that it tends to boomerang. Turning to the variety of advice services available, she points out, one is confronted, once again, with the inescapable necessity to choose one. As one might expect, this becomes a kind of psychological (quasi-Hegelian) dialectic that moves from the initial necessity to choose, to the negation of one's own choice through seeking advice, to a sublation of the choice one tried to avoid, and so on, in the process exacerbating the pressure on oneself to make choices. Hence the mounting anxiety and insecurity that often leads to depression.

There are other factors to consider, too. In answering the question, why choice makes us anxious, Salecl examines the psychological mechanisms accompanying the experience of being overwhelmed by a plethora of options, for example when buying cheese. These typically progress from confusion in the face of a vertigo-inducing variety of possibilities, through anger at oneself for one's indecisiveness, to suspicion and resentment of 
supposed "help" offered by authorities available for consultation. Such an experience illustrates, according to Salecl (2010: 15), "some of the reasons why overwhelming choice can increase our anxiety and feelings of inadequacy". Invariably the person in such a situation falls back on either a random choice, because of volitional paralysis when confronted by a dizzying scale of alternatives, or on the banal option triggered by an "automatic" awareness of the most advertised product.

To this one could add the well-known Lacanian insight, that one's desire is really the Other's desire (Lacan, 2007: cf 525) - which, in the present context, manifests itself in the worry that one's choice of product might be judged by others (one's guests, for example) as being somehow wrong or in bad taste. This sometimes reaches the point where people may even experience the need to choose as traumatic, and Salecl (2010:17) lists some of the grounds for this: the desire to make an "ideal choice", the question of others' comparative opinion about one's choice, the feeling that there is no ultimate social authority (who could obviate one's own need to make certain decisions) and the fear that your choice is not really free, but always already predetermined by others. The last of these is related to her earlier discussion of ideology, and is germane to the issue at hand, given the usual persistence of an overall pattern of behaviour. One unwittingly contributes, albeit negatively, to the reinforcement of an ideology, Salecl (2010) observes, by not openly declaring one's disbelief in its precepts. Paradoxically, therefore, because most people tend to believe that they are exceptions to the rule of subscribing to an ideology - not realizing that most other people feel the same way - it is allowed to persist, together with its concomitant deleterious effects on individuals. Sometimes these effects are physically visible, such as when we hang our heads and cast down our eyes in shame - a frequent occurrence in the society in thrall to the ideology of choice, as Salecl's discussion of such instances, where people are ashamed of their choices for a variety of reasons, clearly shows.

With fine nuancing and a manifest sensitivity to the often paradoxical consequences of being incessantly confronted by the need to make decisions regarding the glut of available options, Salecl (2010) explores the manifold instances of self-doubt, uncertainty and anxiety that are inseparably intertwined with the culture of choice. One of the ironies of this culture, for example, is the valorisation of "self-mastery" and restraint that accompanies its promotion, which turns out to be a source of self-doubt because of nagging feelings of failure. The irony deepens when one compares the objective of such putative (psychological) self-mastery, which is primarily economically motivated, with that which Foucault (1988) found among those individuals, during the Hellenistic era, who dedicated themselves to the "care of the self". For the latter this entailed rigorous discipline of a physical as well as discursive nature, guided by the objective, to gain selfmastery to be able to withstand and overcome the vicissitudes of life which exceed one's personal control. 
The central paradox of the culture of choice, as formulated by Salecl (2010: 149), is perhaps this: "Choice about the organisation of society is offered and denied at the same time. Liberal democratic capitalism glorifies the idea of choice, but with the proviso that what is on offer is primarily a consumerist model of choosing. The choice of a new form of social organisation, of different ways in which society might develop in the future and especially the possibility of rejecting capitalist society as we know it all appear not to be available as choices."

Not even personal relationships are exempt from the negative psychological effects of the tyranny of choice. What Salecl discusses under the rubric of "love choices", which really amounts to "hooking up", epitomises what is most conspicuous about dating today, in so far as it observes the principle of steering clear of real intimacy - which is always accompanied by the risk of getting hurt - in favour of what she terms "the mechanics of contact". "'Hook-up' culture is all about choice", she says, and continues, "We have so many options in every aspect of life that the choice of emotional attachment is not only an added burden but also an impediment to the total freedom we are meant to value. Someone who gets attached too quickly has supposedly not fully profited from that freedom." (Salecl, 2010: 76) The link between "hook-up" culture and the social gains, on the part of women, during the 1960s, is made clear when Salecl points out that it is often justified as a practice which prevents especially women from attaching themselves to a male partner too soon, in this way allowing them to make a better, more informed choice later.

From this perspective, the practice of hooking up is supposed to enable women to behave in the same way that men used to behave, namely, to spend a night randomly with someone, avoiding the investment of feelings, and ignoring any possible emotional consequences. Paradoxically, however, although all of this is done for the sake of "choice and control", Salecl insists, hook-up culture is inseparable from uncertainty. In spite of supposedly liberating young people from the burden of attachment, it encumbers individuals with something else - "insecurity, anxiety and guilt". Moreover, regardless of the connotation of casual contact, without emotional attachment, that clings to "hooking up", one sometimes gets emotionally involved despite one's "best" intentions. And given the norms governing relationships conceived of as casual encounters, such a person is not supposed to admit it to herself or himself, let alone to the person they have developed "feelings" for. Small wonder that, in such cases, it leads to feelings of guilt, anxiety and inadequacy. Clearly, although the culture of choice is glorified in contemporary societies, there is another side to it which suggests that it is overvalued.

\section{The price of adaptation to neoliberal society}

It is well known that Lacan opposed "adaptation" to society as an objective of psychotherapy, and particularly in the case of psychoanalysis. In Lacan's (1997: 82) 
own words: "There are always things that don't hang together. This is an obvious fact, if we do not begin with the idea that inspires all classical, academic psychology, which is that human beings are, as they say, adapted beings, because they are living, and therefore it must all hang together. You are not a psychoanalyst if you accept this. To be a psychoanalyst is simply to open your eyes to the evident fact that nothing malfunctions more than human reality."

This, in inimitable Lacanian seminar-style, is as much as saying that it is constitutive of human subjects to be maladapted beings, even - or perhaps especially - when one believes that you have adjusted supremely well to social, political and economic circumstances. Why? Because such adjustment, or adaptation, is always predicated on a more or less imaginary or hallucinatory relationship with extant social reality, which assumes the form of a "will to illusion", to being deceived. The subject, in other words, is fundamentally alienated from "itself", from the subject of the unconscious, and "misrecognizes" itself in the ego-adaptations to a social reality that amount to attempts at "rational" mastery. To adapt to a social reality that is essentially the product of fantasy is therefore to exacerbate the subject's self-alienation.

According to Lacan the adjustment at stake here implicates orthodox psychoanalytic practice (let alone mainstream psychology), which has promoted a "reinforcement of the ego" at every level, to equip it with the strength to "manage" conflicts and "adapt itself to reality". Perhaps surprisingly, the answer to the question concerning the specific "reality" that the subject must adapt itself to is none other than "the given social reality in which the analysand exists" (Van Haute, 2002).

If adaptation to societal norms is the rule rather than the exception, one should not lose sight of the fact that these norms change over time - Victorian society, with its rigid structures of authority, is a far cry from contemporary, so-called "permissive" society. Hence, adaptation to contemporary society entails conforming to the demands of a neoliberal, market-oriented capitalist society; witness the culture of choice, discussed earlier. Instead of overt obedience to the patriarchal representatives of putative "absolute" religious authority, for example, "obedience" today assumes the guise of subjects acting conscientiously in accordance with a host of expectations dictated by the market: optimising one's choice across a wide range of products and services, submitting to regular "audits" of their work-performance, performing intermittent self-assessments in the workplace, dutifully (if ruthlessly) competing with colleagues for promotion (even if the personal cost is pervasive anxiety or depression), routinely having to meet production deadlines, displaying the outward signs of success (in your choice of clothes, smartphone, motor car, house or apartment) and of enjoyment, which supposedly represents successful competition and consumption (Salecl, 2010). 
It appears that the neoliberal transformations in working conditions have had a farreaching impact on people's health. While I have so far mainly focused on evidence of suffering, such as anxiety, self-doubt and uncertainty, in a largely non-pathological sense, psychoanalyst Paul Verhaeghe draws attention to pathologies and personality disorders that have been proliferating under social conditions engendered by the neoliberal, market-based economy. The price one has to pay for such successful adaptation to neoliberal society is graphically depicted in Verhaeghe's What about me? The struggle for identity in a market-based society (2014). At the outset he states: "The neo-liberal organisation of our society is determining how we relate to our bodies, our partners, our colleagues, and our children - in short, to our identities. And you can't get much more disordered than that. I take my lead here from Sigmund Freud in his Civilisation and its discontents" (2014: location 59).

After a thorough reconstruction of the provenance and character of neoliberalism, Verhaeghe (2014) turns his attention to the question of the link between living in a society dominated by this "narrative" or ideology and the psychological well-being of people. He sets the scene by outlining the differences between the "biopsychosocial" psychiatric model, which focuses on the individual situation of a patient within a broader context, and the "illness" or medical model. Verhaeghe argues that, despite the dominance of the "illness model" in psychiatry and psychology, which assumes that pathological symptoms invariably manifest underlying physical processes that remain the same over time (hence this diagnostic model lets everyone, from psychologists and psychiatrists to parents and teachers, "off the hook"), there are growing signs of people realising that psychic pathologies reflect social censure on the basis of accepted social norms at any given time (which Foucault [1980] also pointed out in the first volume of his History of sexuality). So, for example, Verhaeghe points out, both the British Psychological Society and the World Health Organisation recently openly criticised the illness paradigm by pointing out that diagnoses of "mental disorders" under its regime (as articulated in the canonical DSM) ignore the conspicuous fact, that they are based on prevailing social norms. That is, far from representing judgments rooted in scientifically "objective" knowledge, they are themselves symptoms of social and economic factors from which individuals cannot always escape, such as crime, violence, poor housing and debt, to which one could add neoliberal pressure to outperform one's colleague-competitors.

In sum, Verhaeghe argues persuasively for the view that problems such as "mental disorders" are fundamentally tied to prevailing social and economic conditions. At present, according to him (Verhaeghe, 2014: location 2339): “... we see an avalanche of depression and anxiety disorders among adults, and ADHD and autism among children. This is most marked in the rise in medication. According to official figures, in 2009 one in every ten Belgians was taking antidepressants, and between 2005 and 2007 the 
number of Ritalin prescriptions doubled. In 2011, the use of antidepressants in the Netherlands had gone up by 230 per cent over a period of 15 years; prescriptions for ADHD medication increased annually by more than 10 per cent, with the result that in 2011 the number of prescriptions exceeded one million. Social phobia among adults is currently such a serious problem in the West - despite it being one of the securest regions in the world - that in 2000 the Harvard review of psychiatry referred to it as the third most frequent psychiatric disorder after depression and alcoholism. Is it too far-fetched to assume that this general fear of others is connected to the exponential increase in evaluations, audits, performance interviews, and CCTV cameras, combined with the disappearance of authority and trust?"

It is not surprising to find that social phobia and performance anxiety commonly occur among working people today (and even executives are not exempted from this). In a society where those around you in the workplace either fall into the category of competitors (including your best friends at work) or those who have the task of evaluating your own performance (sometimes they are both), it is difficult not to experience anxiety intermittently, which could easily develop into something chronic. Social phobia has the same origin - involuntarily, you start fearing people's motives when they talk to you about your work, and again this could burgeon into a general condition. The proliferation of problems relating to "mental health" today have to be seen in this light. The neoliberal practice of salary differentiation, linked to performance, and the resulting income inequality (characteristic of neoliberal societies) are crucial in this regard.

Verhaeghe - no doubt anticipating accusations of not being sufficiently "scientific" in his writing - therefore turns to the work of two eminent, widely respected social epidemiologists, Richard Wilkinson and Kate Pickett (who have conducted studies on the link between people's health, broadly speaking, and the society they live in) - to validate his argument. Their findings are unambiguous (Verhaeghe, 2014: location 2365): “... an increase of this kind [income inequality] has far-reaching consequences for nearly all health criteria. Its impact on mental health (and consequently also mental disorders) is by no means an isolated phenomenon." The key factor in their study proved to be stress, which has been shown to have an impact on human cardiovascular systems as well as immune systems. And stress (indirectly it seems to me that one can add anxiety and social phobia) is directly linked to income inequality. A salient conclusion of Wilkinson's first book (The impact of inequality: How to make sick societies better) was already that in a city or a country where there is high income inequality "... the quality of social relationships is noticeably diminished: there is more aggression, less trust, more fear, and less participation in the life of the community". One should keep in mind that income inequality is directly linked to differences in social status. And not surprisingly, Verhaeghe points out that low social status has a "determining effect on health". He 
therefore arrives at the startling conclusion, that even in "prosperous... Western Europe, it isn't the quality of health care...that determines the health of the population, but the nature of social and economic life. The better social relationships are, the better the level of health" (Verhaeghe, 2014: location 2375). And health has been deteriorating steadily under the neoliberal regime.

It may seem as if the "disorders" Verhaeghe refers to contradicts Parker's (2011) claim, that the behaviour of the subject under capitalism displays the structure of obsessional neurosis. This is not the case, however. As Parker (2011) also indicates, a host of pathological conditions accompanies the behaviour of the subject of capitalism, which displays the structural features of obsessional neurosis, such as ineradicable anxiety and doubt-based, repeated performance of certain work-procedures. As might be expected, there is a strong connection between obsessional behaviour and anxiety, which Lacan (1962/63: 68) formulates causally as follows: "Anxiety is not doubt; anxiety is the cause of doubt". In my own judgment, therefore, these findings on Verhaeghe's part are compatible with the present argument, insofar as, for reasons outlined above, it demands of workers (executives included) a painfully repetitive and stressful, conscientious commitment to productive work, as if on the tacit assumption or belief that something terrible would happen to them if they should fail to obey this "categorical imperative" (Freud, 1919). And anxiety or fear and depression are always waiting in the wings, lest one should feel, as one invariably does, sooner or later, that one is not meeting expectations (which have by then been internalized).

\section{Signs of growing resistance to capitalist work}

In the light of the above it is interesting to note that, according to Silvia Federici (2013), there are signs that the state of affairs under neoliberal capitalism has evoked a growing resistance. This has to be seen against the backdrop of her claim, that "... throughout its history, capitalism has transformed our bodies into work-machines" (Federici, 2013: 3), and that both the state and disciplines like philosophy and psychology have been actively involved in this process. Her contention is that "rethinking" how this has occurred enables one to understand the crisis faced by capitalism today, as manifested in " ... the social and individual pathologies, the resistances, the refusals, the search for new anthropological paradigms ..." Moreover, she adds that this is something to which a "reconstructed psychology cannot be indifferent, if it wishes to break with its history of complicity and collaboration with Power" (Federici, 2013: 3).

What was argued earlier concerning "adaptation" is confirmed by Federici's elaboration on the contribution of so-called "industrial/organizational psychology" to the systematic development of a psychology of conformity to promote optimal discipline and productivity on the part of labouring subjects in the context of 
capitalist production - something that resonates with Foucault's (1995) sustained argument that, in modern society, various mechanisms of discipline have reduced subjects to "docile bodies" which are politically impotent but economically productive (Olivier, 2010).

Federici (2013) discerns three lessons that may be learnt from the complex history of capitalism's relentless transformation of bodies into labour power: that the "mechanization of the body" is demanded by work-discipline under capitalism, concomitantly annihilating the body's creativity and autonomy; that the complicity of psychologists with this process (ignoring workers' abhorrence of the regimentation of their minds and bodies by industrial labour, for example) amounts to their betrayal of the assumptions on which their claim to be doing science rests; and that the crisis of contemporary capitalism is uncovered by this history. This includes the attempts, since the turning-point of the 1960s, to contain the crisis through a "global reorganization of the work process", the indications that disciplinary mechanisms to ensure production no longer function, and the multiple manifestations of the "... refusal to reduce one's activity to abstract labor, to renounce the satisfaction of one's desires, to relate to one's body as a machine, and a determination to define our body in ways independent of our capacity to function as labor-power" (Federici, 2013: 6-7).

Given this crisis it makes perfect sense that, since the inception of the neoliberal phase of capitalism around the 1970s, the preponderant approach aimed at defusing the "refusal" alluded to by Federici has been the creation of an illusory "freedom" - freedom to compete, freedom to advance in one's career, freedom to develop levels of "excellence" (which has been one of the chief lures for unsuspecting workers who are keen to progress to higher income levels in their jobs), and freedom of movement from one position to another. In fact, the more highly skilled you are, the greater your "upward" mobility under neoliberal capitalism; hence the term "Yuppie" (young, upwardly mobile worker). In the light of what was pointed out earlier regarding the price of "adaptation", it should be apparent that such upward mobility does not come without the suffering peculiar to the marketplace of sought-after worker skills. A pertinent example of this in South Africa and elsewhere are the attempts, on the part of employers such as universities, to retain what is labelled "gold-collar workers" because of their financial value to the institution. Although such well-qualified and, in the case of universities, research-productive employees are generally well-remunerated, the catch is that they are under constant pressure to produce the expected number of research "outputs", or to attract large funding from corporations, with the result that their work is invariably accompanied by high stress levels. This is clearly demonstrated by a recent case in Britain, where a professor of medicine committed suicide when he was told that he would be dismissed ("sacked") because he had failed to generate the required $£ 200000$ 
per annum (Colquhoun, 2014). Clearly, under the neoliberal regime many universities are run more like businesses than as institutions of higher learning by a ruthless cohort of managers, with dire results for the health of academic staff.

The restructuring and reorganisation of labour at all levels can further be understood, according to Federici (2013: 7), in terms of the "precarization and flexibilization of work", as well as the systematic "disinvestment by the state in ... social reproduction". On the one hand, although they are not exempt from the stress accompanying pressure to perform, those with the "rare skills" required by the restructured economy (the so-called "gold-collar workers") are in a position to exploit the demand for their abilities (as "knowledge workers"), but on the other hand it has resulted in the emergence of "a worker that is depersonalized, adaptable, ready at any moment to change occupation" (Federici, 2013: 7), something noted by Verhaeghe (2014) too. ${ }^{1}$

Taking into consideration that this stress-inducing situation is further exacerbated by the ongoing automation and computerization of work, requiring what Federici (2013) describes as "dehumanizing, militaristic types of behavior", her summary of the concomitant suffering serves as a mirror for the contemporary subject, and resonates with Verhaeghe's findings, discussed earlier. For instance, Federici (2013: 7) notes: "Indeed, the abstraction and regimentation of labor has reached today its completion and so has our sense of alienation and de-socialization. What levels of stress this situation is producing in our lives can be measured by the massification of mental diseases - panic, anxiety, fear, attention deficit, the escalating consumption of drugs from Prozac to Viagra ... Fear and anxiety are only one aspect of the terror that today is employed to suffocate the growing revolt against the global work machine. Equally important has been the militarization of everyday life, now an international trend, preceding September 11."

It appears, therefore, that there is ample reason today for the multiple emerging signs of resistance to the relentless, encompassing strategy of global capital to ensure that the economic wheels keep turning. What Federici has brought to light is highly significant: that increasing numbers of people are actively pursuing alternative ways of living, unregulated by work that is subject to the identity-destructive market, that workers are turning to ways of protesting that differ from the customary strike, and that discursive practices linked to the "commons" are engendering practices like time-banking and new community-oriented initiatives (including the burgeoning of communes). One is witnessing nothing less than the gestation of a new imaginary, as the globally spreading popularity of tattoos (arguably a

\footnotetext{
In South Africa this is perceptible in the fact that the entire school education system is geared to the production of such "flexible workers" - a shocking example of collusion between the state and neoliberal capital. See in this regard Du Plessis (2012).
} 
kind of throwback to pre-modern markers of "tribal" belonging, resurfacing in the context of resistance to the culturally homogenising tendency of capitalist globalisation), the preference for androgynous gender models and the impact of a movie like James Cameron's Avatar with its indictment of capitalist, eco-destructive exploitation, combined with a valorization of the unity of human(oid) and nature, further show (Olivier, 2010a; 2011).

Federici (2013: 9) concludes her far-reaching paper with important questions: "What would a psychology be like that measured the mental and physical damages caused by capitalism? That recognized that stress, anxiety, dread, insecurity, alienation from others and from oneself, are inevitable results of a system that normalizes the destruction of our livelihood, our social relations, our creativity? That would refuse to accept the transformation of living labor into dead labor as a norm, and therefore refused the use of torture, not only in its literal form, but in its daily appearance in the form of the capitalist organization of work? Answering these questions is the task ahead of us."

\section{Conclusion}

To conclude, one should take seriously Renata Salecl's (2010) repeated observation, that the ideology of choice, so prevalent in contemporary society, persisting even (perhaps surprisingly) in the wake of the recent global financial crisis, functions to distract one's attention from the need for fundamental economic and social change. In other words, it is an ideological mechanism that ensures neoliberal capitalism's perpetuation, for as long as people are preoccupied with all its attendant psychological difficulties, such as self-doubt and anxiety, which focus attention on ostensible failings of the individual subject, instead of on the necessity to change the extant economic system. The difference between the Hellenistic Roman era, referred to earlier regarding Foucault's (1988) examination of the "care of the self" as model of self-mastery, and today, is instructive here. The present and the Hellenistic era display some similarities, chief among which is perhaps that in both cases individuals could easily feel lost and overwhelmed by the sheer magnitude of the world they inhabit(ed). After all, when the demise of the Greek city-states made way, first, for Alexander's Macedonian conquests and later for the Roman Empire, people had to accept that, unlike the situation in the Greek polis, where citizens could exercise a measure of influence over their own economic and political circumstances, the far-flung Empire precluded such participation for all but the privileged few. In today's globalized world feelings of being insignificantly "small" may be similar to those of centuries ago, but there is an important difference, namely, that the possibility of contributing to economic and social/political change today far outweigh that of Roman times.

Hence, the following remark by Salecl (2010: 24) may appear to apply to both historical eras, but in fact only applies to the present: "The more isolated we become from a real 
engagement with the social and political sphere, the more we are propelled toward selfmastery". Two thousand years ago the opportunity did not exist for the vast majority of people to "engage with the social and political sphere", but today it does, even if it means confronting the juggernaut of neoliberal capitalism and its paralyzing ideology of choice, with a view to finding an alternative to it. It is fitting to quote Salecl (2010: 148) at length here: "Today's capitalist society, with its insistence on the idea of choice, masks class difference as well as racial and sexual inequality...The feeling of shame for being poor and of guilt for not getting further up the ladder of economic success has replaced the fight against social injustice. And the anxiety about not being good enough has pacified people, leading them not only to work longer hours but often to work just as hard at their appearance. Choice can open up the possibility of change at the level of society, but only when it is no longer perceived as solely an individual prerogative. The success of the ideology of choice in today's society has been in blinding people to the fact that their actual choices are becoming severely limited by the social divisions in society and that issues such as the organisation of labour, health and safety, and the environment appear more and more beyond their choice. At the level of society we are therefore losing the possibility of choice in terms of change in power relations as we know them. Not surprisingly, the ideology of choice goes hand in hand with the New Age ideology that promotes living in the moment and accepting things as they are."

One thing that the culture of choice inculcates, and may go unnoticed by many people who are preoccupied with the task of fashioning themselves according to the precepts of this pervasive ideology, is the fact that it goes hand in hand with the kind of individualism on which neoliberalism thrives. As Salecl (2010) demonstrates so well, however, there is plenty of evidence that suffering, especially in the form of a cluster of interrelated psychic phenomena - such as anxiety, self-doubt, depression and debilitating uncertainty is inseparable from the culture of choice. Corroborating her insights, in his sustained investigation of the hidden ties between depression, mourning and melancholia, Darian Leader (2008: 1-2) highlights the “... negative side of modern individualism, where each of us is taken to be an isolated agent, cut off from others and driven by competition for goods and services in the market-place rather than by community and shared effort". It is no accident that Leader uncovers the crucial role that communal ties and rituals have traditionally played in coming to terms with loss through mourning, which is discouraged in contemporary society (preoccupied as it is with "quick fix" pharmaceutical treatment of what are symptoms, rather than underlying conditions).

What the present inquiry has shown, then, can be summarized as follows. As Salecl (2010) and others have indicated, we live in a severely divided society, where, on the one hand, capitalism benefits from the divisions, thriving on the individualistic ideology of choice at every level, from product choice to service choice (like advice services), concomitantly 
generating uncertainty and feelings of failure in consumers, which, in their turn, generate the need for new choices in the advice and self-help industries. And instead of addressing the root of the problem - the neoliberal organization of societies - individuals' attention is conveniently diverted to themselves as being responsible for their failures and feelings of inadequacy. What Parker (2011) has highlighted, that the typical subject of capitalism is the obsessional neurotic - which has here been understood in Freud's "patho-analytic" sense of a pathology that resonates, and hence throws light on widespread patterns of behaviour in "normal" society - may be perceived as concentrating in itself the modes of suffering identified by Salecl, Verhaeghe and Federici.

I would like to conclude this reflection on some of the kinds of suffering that seem to be inseparably bound up with neoliberal capitalism today by drawing attention, briefly, to the recent work of Michael Hardt and Antonio Negri, alluded to at the outset in this article. In Declaration they articulate the global crisis of the present era in terms of four "figures", or "subjectivities" produced under conditions of what they call "Empire" (2001), or the new sovereign economic and political power ruling the world. They summarise these figures as follows (Hardt \& Negri, 2012: 9): "The triumph of neoliberalism and its crisis have shifted the terms of economic and political life, but they have also operated a social, anthropological transformation, fabricating new figures of subjectivity. The hegemony of finance and the banks has produced the indebted. Control over information and communication networks has created the mediatised. The security regime and the generalised state of exception [a reference to Giorgio Agamben's work - B O] have constructed a figure prey to fear and yearning for protection - the securitised. And the corruption of democracy has forged a strange, depoliticised figure, the represented. These subjective figures constitute the social terrain on which - and against which - movements of resistance and rebellion must act ... these movements have the ability not only to refuse these subjectivities but also to invert them and create figures that are capable of expressing their independence and their powers of political action."

Hardt and Negri's elaboration on each of these subjectivities produced under current socio-economic and political conditions, which are all intertwined, highlights just how hamstrung people in today's world are by the power of capital. "The indebted", for example, is a figure that marks the general condition of being in debt today, and their enumeration of all the levels and sites of debt (including house mortgages, student loans, car-instalments and personal loans to pay any number of other debts) resonates with the experience of most people today. Loans have indeed become the "primary means" to be able to live in a social context. But more than that, apart from "welfare" having turned into what they call "debtfare", debt may be said to control everything, from consumption to your very survival (a claim that echoes Deleuze's [1992] observations on "societies of control"). Without exaggerating, Hardt and Negri

PINS [Psychology in Society] $48 \cdot 2015 \mid 18$ 
point out that it determines one's choices, such as those confronting you when you finish your university study with a repayable loan, and have to find a job to be able to pay off your debt, or being held captive to work uninterruptedly by a mortgage on an apartment, lest you lose it. They compare debt to the work ethic, with the difference that the latter is "born within the subject", while debt starts as an external force, only to invade one's subjectivity later. Under debt, for which you are responsible, guilt (of a financial kind) becomes a "form of life". "The indebted" is the contemporary, non-dialectical counterpart of Hegel's slave, and it has been spawned by neoliberal, market-based capitalism.

In the light of the conditions of provenance of all of these modes of suffering and hardship in contemporary societies, could anyone deny that they are inseparable from the hegemonic neoliberal economic system? Furthermore, how long will it take before a significant number of people will realise that, instead of being able to deliver the fulfilment it routinely promises in advertising images of glamour and happiness (Olivier, 2013), neoliberal capitalism is a source of unmitigated hardship and suffering?

\section{References}

Colquhoun, D (2014) Publish and perish at Imperial College London: The death of Stefan Grimm. http://www.dcscience.net/2014/12/01/publish-and-perish-at-imperialcollege-london-the-death-of-stefan-grimm/ Retrieved: 1/3/2015.

Deleuze, G (1992) Postscript on the societies of control. October, 59, 3-7.

Du Plessis, C (2012) The constitution of the flexible generalist: A Foucaultian and Althusserlian analysis of the basic education system of South Africa.

Unpublished Master's dissertation. Port Elizabeth: Nelson Mandela Metropolitan University.

Federici, S (2013) With philosophy and terror: Transforming bodies into labor power, in Marvakis, A et al (eds) Doing psychology under new conditions. Concord, Ontario: Captus Press Inc (pp 2-10).

Foucault, M (1980) The history of sexuality, Volume 1: An introduction. New York: Vintage Books (1976-French).

Foucault, M (1988) The care of the self. The history of sexuality, Volume 3. New York: Vintage Books (1984-French). 
Foucault, M (1995) Discipline and punish: The birth of the prison.

New York: Vintage Books (1975-French).

Freud, S (1919) Totem and taboo: Resemblances between the psychic lives of savages and neurotics. New York: Moffat, Yard and Company (1913-German).

Freud, S (2011) On the grounds for detaching a particular syndrome from neurasthenia, in Freud - Complete works. Ivan Smith e-book (pp 325-349) (1894-German).

Freud, S (2011a) Notes upon a case of obsessional neurosis, in Freud - Complete works. Ivan Smith e-book (pp 2125-2194 (1909-German).

Freud, S (2011b) New introductory lectures on psycho-analysis, in Freud - Complete works. Ivan Smith e-book (pp 4617-4778) (1933-German).

Fukuyama, F (1992) The end of history and the last man. New York: The Free Press.

Hardt, M \& Negri, A (2001) Empire. Cambridge, MA: Harvard University Press.

Hardt, M \& Negri, A (2005) Multitude: War and democracy in the age of Empire. New York: Penguin Books.

Hardt, M \& Negri, A (2012) Declaration. New York: Argo Navis Author Services.

Klein, N (2007) The shock doctrine: The rise of disaster capitalism. London: Allen Lane.

Lacan, J (2012) The seminar of Jacques Lacan, Book X. Anxiety. http://www. lacaninireland.com/web/wp-content/uploads/2010/06/Seminar-X-Revised-by-MaryCherou-Lagreze.pdf (2004-French).

Lacan, J (1997) The seminar of Jacques Lacan, Book III. The psychoses. New York: W W Norton (1981-French).

Lacan, J (2007) The direction of the treatment and the principles of its power, in Écrits. The first complete edition in English. New York: W W Norton and Company (pp 489-542 (1966-French).

Leader, D (2008) The new black: Mourning, melancholia and depression. London: Hamish Hamilton. 
Olivier, B (2010) Foucault and individual autonomy. South African Journal of Psychology, 40(3), 292-307.

Olivier, B (2010a) AVATAR: Ecopolitics, technology, science and myth. South African Journal of Art History, 25(3), 1-16.

Olivier, B (2011) Film as communicational mediation of the ecological crisis: Avatar and The Road. Communicare - Journal for Communication Sciences in South Africa, 30(1), 66-85.

Olivier, B (2013) Psychoanalysis and social change. Psychotherapy and Politics International, 11(2), 114-126.

Parker, I (2011) Lacanian psychoanalysis: Revolutions in subjectivity. London: Routledge.

Salecl, R (2010) Choice. London: Profile Books.

Van Haute, P (2002) Against adaptation: Lacan's "subversion" of the subject. New York: Other Press (Kindle edition). (nd-Dutch/Flemish.)

Van Haute, $\mathrm{P}$ (2013) Het project van een pathoanalyse van het bestaan in Freuds Drie verhandelingen over de theorie van de seksualiteit (1905), in Van Haute, P \& De Vleminck, $J$ (eds) Freud als filosoof: Over seksualiteit, psychopathologie en cultuur. Kalmthout: Pelckmans Uitgeverij (pp 31-47).

Verhaeghe, $\mathrm{P}$ (2014) What about me? The struggle for identity in a market-based society. London: Scribe Publications (Kindle edition). (2012-Dutch).

Žižek, S (1995) The deadlock of "repressive desublimation", in The metastases of enjoyment. Six essays on woman and causality. New York: Verso (pp 7-28). 